\title{
Evaluating the diameter of eyedropper tips using a computer vision system
}

\author{
Avaliação do diâmetro de bicos de conta-gotas de colírios por \\ visão computacional
}

\author{
Edicley Vander Machado', Priscila Cardoso Cristovam², Denise de Freitas², José Álvaro Pereira Gomes², \\ Vagner Rogério dos Santos² \\ 1. Instituto Federal de Educação, Ciência e Tecnologia de São Paulo, São Paulo, SP, Brazil. \\ 2. Department of Ophthalmology and Visual Science, Escola Paulista de Medicina, Universidade Federal de São Paulo, São Paulo, SP, Brazil.
}

\begin{abstract}
Purpose: This study aimed to determine the variation in diameters of outer and inner apertures of eyedropper tips using a computer vision system. Standardizing the size of eye drop nozzles is crucial to reduce the treatment cost of chronic eye diseases and to ensure a continued use of medication. An eyedropper volume of $>20 \mu \mathrm{L}$ (maximum storage of the conjunctival sac) causes medication wastage and increases treatment costs. Methods: We measured the diameters of the outer and inner apertures of eyedropper tips and evaluated variations in diameters using a computerized visual inspection system. Results: The computer visual inspection system identified anomalies in the apertures of eyedropper tips that resulted in diameter variations. Conclusions: The results of the present study show discrepancies in diameters of eyedropper tips, suggesting a variation in eyedropper size and medication wastage.
\end{abstract}

Keywords: Lubricant eye drops; Drug packaging; Eyedropp size; Diameter variation; Health care costs; Computer vision system

RESUMO | Objetivo: Este estudo teve como objetivo determinar a variação dos diâmetros das aberturas externa e interna dos bicos conta-gotas utilizando sistema de visão computacional. A padronização do tamanho dos colírios conta-gotas é importante para reduzir o custo do tratamento de doenças crônicas e garantir o uso contínuo de medicamentos. O volume da gota maior do que $20 \mu \mathrm{l}$ (volume de armazenamento máximo do saco conjuntival) gera desperdício da medicação e aumenta o custo do tratamento. Métodos: Medimos os diâmetros das aberturas externa e interna

Submitted for publication: January 10, 2018

Accepted for publication: April 22, 2018

Funding: No specific financial support was available for this study.

Disclosure of potential conflicts of interest: None of the authors have any potentia conflicts of interest to disclose.

Corresponding author: Priscila Cardoso Cristovam.

Rua Pedro de Toledo, 669 - 4ª andar frente - São Paulo, SP - 04039-032 - Brazil E-mail: pricristovam@hotmail.com

Experimental protocols: Approved by the Institutional research ethics committee (no 1092211014) at Federal University of São Paulo. das pontas dos conta-gotas e avaliamos as variações no diâmetro usando um sistema de inspeção visual computadorizado. Resultados: $\mathrm{O}$ sistema de inspeção visual por computador identificou anomalias nas aberturas dos bicos dos frascos conta-gotas que resultaram em variações de diâmetro. Conclusões: Os resultados do presente estudo mostram discrepâncias nos diâmetros dos bicos dos frascos dos conta-gotas, sugerindo uma variação no tamanho das gotas e no desperdício de remédios.

Descritores: Colírio lubrificante; Embalagem de medicamentos; Tamanho da gota; Variação do diâmetro; Custos de cuidados de saúde; Sistema de visão computacional

\section{INTRODUCTION}

Some chronic eye diseases decrease visual acuity, possibly resulting in vision loss. The World Health Organization reported that in $2002>161$ million people worldwide have some form of visual impairment, 37 million of whom are blind. In addition, $>82 \%$ of all blind people were of $\geq 50$ years of age ${ }^{(1)}$. Increasing costs associated with public health care has become a serious problem as visual impairment and blindness significantly impact the socioeconomic development of individuals and society ${ }^{(2)}$.

Dry eye syndrome is a multifactorial disease affecting the tear film and consequently the ocular surface ${ }^{(3-9)}$, with epidemiological studies indicating an increasing global incidence of dry eye disease $\mathrm{e}^{(10,11)}$. The use of treatment method depends on the severity of the disease and includes patient education and use of topical (eye drops) and systemic medications. Topical medications include artificial tears, anti-inflammatory drugs (nonsteroidal, corticosteroids, and cyclosporine A), and autologous serum ${ }^{(12-14)}$.

Moreover, glaucoma has a significant financial impact on the health care system owing to the frequent use of 
drugs, surgical procedures, consultations, and complementary tests involved in glaucoma treatment ${ }^{(15,16)}$.

Most drugs used to treat eye diseases are aqueous solutions containing active ingredients (eye drops). These medications are applied using a wide range of eyedroppers with different types of tips that allow slow dropwise administration of the drug ${ }^{(17)}$. Studies suggest that the lack of uniformity in dropper size results in medication wastage ${ }^{(18,19)}$ because the dropper size should be determined based on the maximum capacity of the conjunctival sac $(20 \mu \mathrm{L})^{(20)}$. Here, we aimed to evaluate variations in the diameters of the outer and inner apertures of eyedropper tips using a computer vision system.

\section{METHODS}

All of the experimental protocols were approved by the Institutional Research Ethics Committee (no 1092211014) at Federal University of São Paulo, and all experiments were performed in accordance with the approved guidelines and regulations.

A computerized visual inspection system was used to measure the dimensions of the outer and inner apertures. Tests were conducted on lubricating eye drops available in the Brazilian market, which were designated as "brand A" and "brand B" and chosen on the basis of the lowest price. We inspected ten $15-\mathrm{mL}$ bottles from two

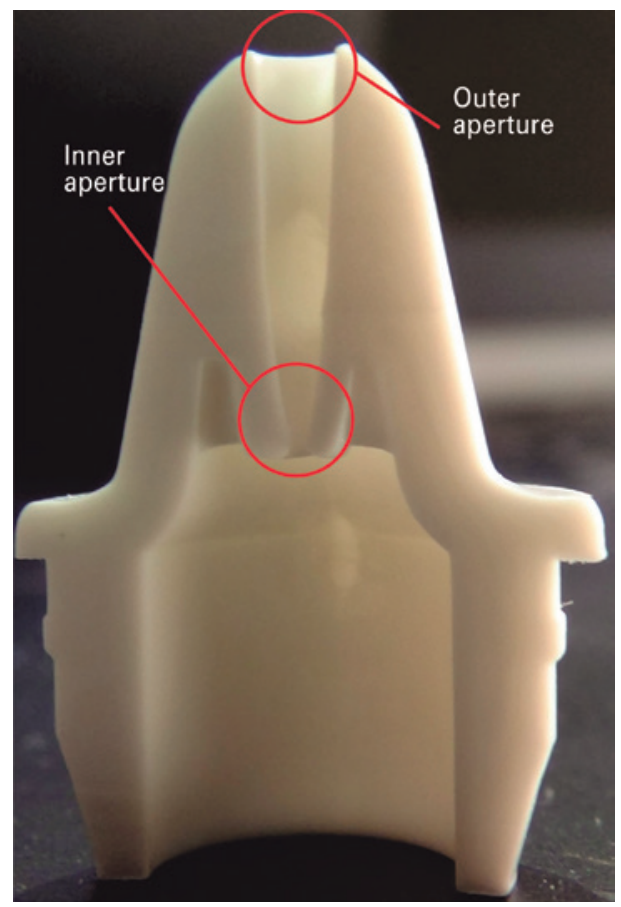

Figure 1. Photograph of the cross-section of an eyedropper tip (Source: author). different brands, five bottles from each brand and from different batches. Figure 1 illustrates the cross-section of the eyedropper tip; the external opening is in the upper portion of the tip, which is easily visualized by the user, and the inner aperture is in the lower portion of the tip, inside the eyedropper.

\section{Computer visual inspection}

An artificial vision system (Omron, Kyoto, Japan) was used to conduct the inspection using the following configuration: FZ5-L355 controller, dedicated software, camera resolution of 2 million pixels, $25 \mathrm{~mm} / 1: 14$ lens, 30-mm spacer, and backlight (Figure 2).

In the present study, we used a backlight, 25-mm lens optical system, and 30-mm spacer to enhance and magnify the diameter of the openings 10 times. Digital images of the eyedropper tips were obtained in pixels.

We inspected the eyedroppers in two stages because the openings have different nominal dimensions and relative positions at the tips: inspection of the outer and inner apertures of the tips, with different distance ratios between the camera and the object, which generated different inspection images.

\section{Statistical analysis}

Descriptive analysis was performed to obtain means $(\bar{x})$ and standard deviations (SD). Data were analyzed using one-way analysis of variance using the SigmaStat software (Systat Software, San Jose, CA, USA). The study groups were subsequently compared, and p-values $<0.05$ were considered statistically significant.

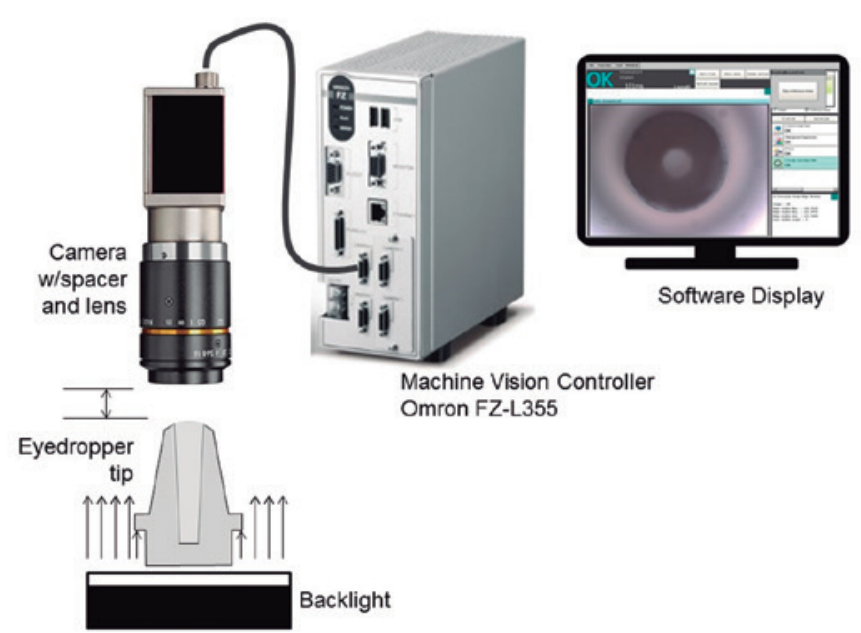

Figure 2. Installation of the computerized visual inspection system (Source: author). 


\section{RESULTS}

The results of inspecting the dimensions of the outer and inner apertures of the eyedropper tips are separately shown.

\section{Inner aperture}

The inner aperture of bottles from brand A indicated variations in the measurements, with an average of $125.9 \pm 5.31$ pixels, corresponding to a difference of 8.6\% (Table 1).

Figure 3 shows deficiencies in the dimensions and variation in the diameters of the openings of the eyedropper tips.

Figure 3 shows an examination of the inner aperture of different bottles from brand A using a computerized vision inspection system. Figure $3 \mathrm{~A}$ shows an opening that is considered adequate (because it has no internal obstructions). Figure 3B demonstrates internal burrs, and Figure $3 \mathrm{C}$ exhibits the undefined shape of the opening. These results demonstrate the non-uniformity of the tips made by the same eyedropper brand.

Due to their small size, we could not measure the inner apertures of eyedropper tips of bottles from brand B, which limited inspection with the optical system.

\section{Outer aperture}

Outer aperture measurements of bottles $(n=5)$ from brands A and B varied by $3.7 \%$ and $2.1 \%$, respectively. In addition, a significant difference was noted in the outer aperture measurements $(p=0.025)$ between brands $A$ and B (Table 2).

\begin{tabular}{lcc}
\multicolumn{4}{l}{ Table 1. Measurements of the inner apertures of eyedropper tips } \\
\hline Bottle & Brand A (pixels) & 土SD (pixels) \\
\hline 1 & 125.1 & $125.92 \pm 5.3$ \\
2 & 120.4 & \\
3 & 121.3 & \\
4 & 131.1 & \\
5 & 131.7 & \\
\hline
\end{tabular}

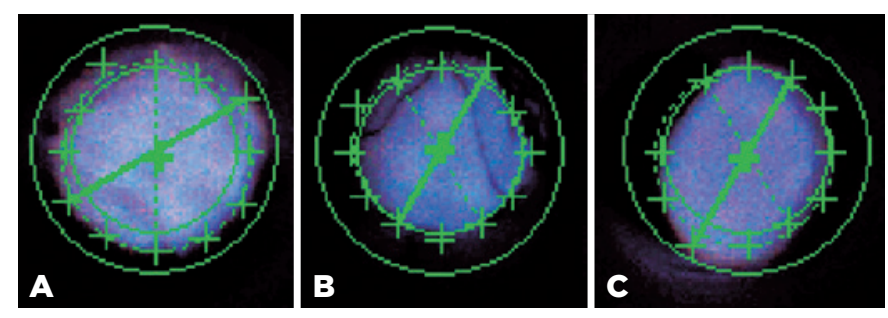

Figure 3. Inner aperture of the eyedropper tip (Source: author). (A) adequate (no internal obstructions), (B) internal burrs and $(C)$ undefined shape of the opening.
The outer apertures exhibited no burrs or anomalies. Figure 4 shows an image of a tip captured by the computerized vision inspection system via diameter inspection.

\section{DISCUSSION}

Considering the increase in the number of elderly people in Brazil, who now represent $7.9 \%$ of the population and are estimated to account for $13.44 \%$ by $2030^{(21)}$, and that the prevalence of eye problems is higher in this population, it is essential to implement solutions to reduce the financial impact of eye treatments on family income within this population.

Optical inspection systems, such as computerized vision inspection systems and laser measurement sensors, are effective strategies for increasing repeatability and reliability and obtaining more relevant information about the processes that can assist in production management ${ }^{(22)}$. Artificial vision system technology is a computational tool for obtaining relevant information for decision making in production lines involving ex-

Table 2. Measurements of the outer apertures of eyedropper tips (Source: author)

\begin{tabular}{lcccc}
\hline Bottle & Brand A (pixels) & \pm SD (pixels) & Brand B (pixels) & $\begin{array}{c}\bar{\chi} \pm S D \\
\text { (pixels) }\end{array}$ \\
\hline 1 & 890.3 & $901.4 \pm 16.0$ & 920.0 & $923.4 \pm 8.1$ \\
2 & 895.4 & 929.9 & \\
\hline 3 & 917.9 & 910.8 & \\
\hline 4 & 884.4 & 930.1 & \\
\hline 5 & 918.8 & & 926.1 & \\
\hline
\end{tabular}

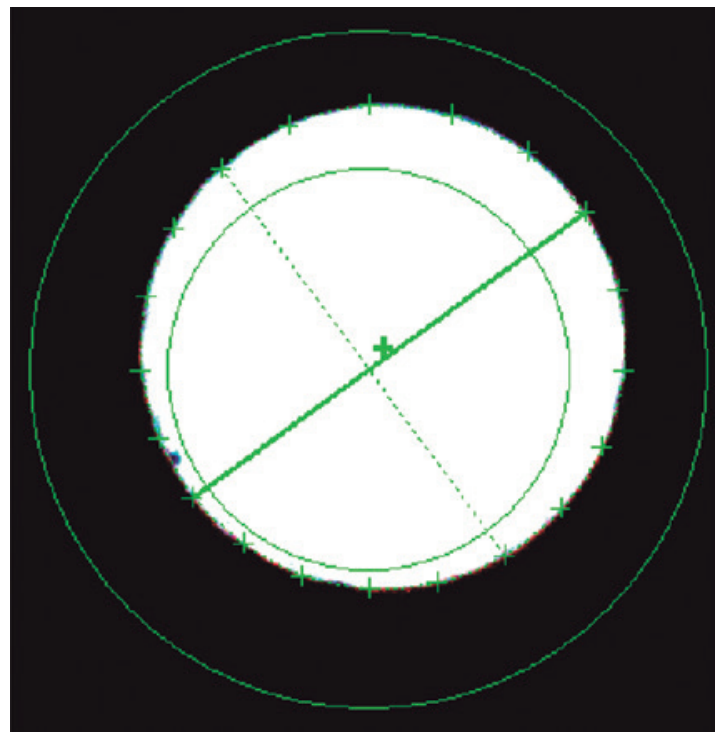

Figure 4. Inspection of the outer aperture of the eyedropper tip (Source: author) 
traction, manipulation, analysis, and automated classification of images or image sequences using a specific computer system ${ }^{(23)}$.

In the field of ophthalmology, vision systems provide automated inspection of processes related to quality assessment, selection, classification, character reading, and object orientation ${ }^{(24)}$. This technology is essential in the manufacturing industry due to the increased demand for traceability and documentation to certify product quality ${ }^{(25)}$.

The number of drops in each bottle determines its yield and is a critical factor in consumer choice ${ }^{(18)}$. Therefore, a drop volume exceeding the recommended value decreases the yield, increases the annual cost of treatment and waste, and can significantly harm the consumer $^{(16,26)}$. A previous study demonstrated that the financial impact on family income is an important factor involved in treatment adherence ${ }^{(26)}$. Reports indicate that in addition to financial issues, a higher drop volume than recommended may cause health problems via systemic absorption through the mucosa in adults and children. The larger instilled volume could be more rapidly drained through the naso-lacrimal duct system. Systemic absorption occurs more easily in children due to their smaller body size and lower systemic metabolizing capacity ${ }^{(27,28)}$. Factors influencing the size of the drops administered using a plastic eyedropper bottle include physicochemical properties of the solution, patient handling of the bottle, and design and characteristics of the eyedropper and bottle ${ }^{(29)}$.

The mass of the dispensed drop is strongly affected by the solution's physicochemical properties, including viscosity and surface tension. Nascimento et al. compared $20 \mu \mathrm{L}$ volumes of the drop mass of five different brands of lubricant eye drops used in ophthalmology. They obtained five $20 \mu \mathrm{L}$ samples of each drug using a micropipette (Eppendorf $20 \mu \mathrm{L}$ ) and weighed the samples on a calibrated Precision Scale (Bioprecisa Electronic Balance FA2104N). Their results suggested the absence of a reference standard for the drop mass of lubricant eye drops considering a $20 \mu \mathrm{L}$ volume ${ }^{(30)}$.

Another factor is drug application and bottle handling, i.e., the way the patient applies the drug. For example, drop formation is influenced by the angle of application $\left(45^{\circ}\right.$ or $\left.90^{\circ}\right)$ and the amount of pressure applied on the bottle ${ }^{(31)}$. Nascimento et al. found that the mean volume per drop exceeded $200 \%$ of the optimum $20 \mu \mathrm{L}$ volume reported in the literature ${ }^{(30)}$. They collected samples of five lubricant drugs used in ophthalmology from four vo- lunteers aged 21-29 years, and each volunteer collected one sample drop 10 times (applied at $90^{\circ}$ ) of each drug.

With respect to the design and physical characteristics of eyedropper tips, the internal shape of the tips directly influences drop size ${ }^{(29)}$. Moreover, these characteristics are determined during the design phase and may suffer variations in the production process. According to the manufacturer, the tips are thermoplastic injection-molded pieces of low-density polyethylene (LDPE), which is softened in a heated cylinder and injected into a mold, hardening and taking the final shape of the mold once cooled. The pieces are subsequently extracted from the mold ${ }^{(32)}$.

Standardization of eyedropper size is necessary in reducing treatment costs of eye diseases and ensuring continuous use of medications without interruptions due to financial reasons, thus benefiting patients as well as society.

The presence of anomalies and lack of standardization of eyedropper tips indicate variations in dropper size and medication wastage. Therefore, standardizing the tip production process is necessary to prevent drug wastage and avoid eye damage due to excessive use of these drugs.

\section{REFERENCES}

1. Resnikoff S, Pascolini D, Etya'ale D, Kocur I, Pararajasegaram R, Pokharel GP, et al. Global data on visual impairment in the year 2002. Bull World Health Organ. 2004;82(11):844-51.

2. Salomão SR, Mitsuhiro MRKH, Belfort Jr R. Visual impairment and blindness: an overview of prevalence and causes in Brazil. Anais da Academia Brasileira de Ciências. 2009;81(3):539-49.

3. Begley CG, Chalmers RL, Abetz L, Venkataraman K, Mertzanis P, Caffery BA, et al. The relationship between habitual patient-reported symptoms and clinical signs among patients with dry eye of varying severity. Invest Ophthalmol Vis Sci. 2003;44(11):4753-61.

4. Adatia FA, Michaeli-Cohen A, Naor J, Caffery B, Bookman A, Slomovic A. Correlation between corneal sensitivity, subjective dry eye symptoms and corneal staining in Sjogren's syndrome. Can J Ophthalmol. 2004;39(7):767-71.

5. Vitale S, Goodman LA, Reed GF, Smith JA. Comparison of the NEI-VFQ and OSDI questionnaires in patients with Sjogren's syndrome-related dry eye. Health Qual Life Outcomes. 2004;2:44.

6. Rieger G. The importance of the precorneal tear film for the quality of optical imaging. Br J Ophthalmol. 1992;76(3):157-8.

7. Liu Z, Pflugfelder SC. Corneal surface regularity and the effect of artificial tears in aqueous tear deficiency. Ophthalmology. 1999; 106(5):939-43.

8. Goto E, Yagi Y, Matsumoto Y, Tsubota K. Impaired functional visual acuity of dry eye patients. Am J Ophthalmol. 2002;133(2):181-6.

9. The definition and classification of dry eye disease: report of the Definition and Classification Subcommittee of the International Dry Eye WorkShop (2007). Ocul Surf. 2007;5(2):75-92. 
10. Iglesias E, Sajnani R, Levitt RC, Sarantopoulos CD, Galor A. Epidemiology of Persistent Dry Eye-Like Symptoms After Cataract Surgery. Cornea. 2018;37(7):893-8.

11. Zou X, Lu L, Xu Y, Zhu J, He J, Zhang B, et al. Prevalence and clinical characteristics of dry eye disease in community-based type 2 diabetic patients: the Beixinjing eye study. BMC Ophthalmol. 2018;18(1):117.

12. Management and therapy of dry eye disease: report of the Management and Therapy Subcommittee of the International Dry Eye WorkShop (2007). Ocul Surf. 2007;5(2):163-78.

13. Behrens A, Doyle JJ, Stern L, Chuck RS, McDonnell PJ, Azar DT, et al. Dysfunctional tear syndrome: a Delphi approach to treatment recommendations. Cornea. 2006;25(8):900-7.

14. Design and conduct of clinical trials: report of the Clinical Trials Subcommittee of the International Dry Eye WorkShop (2007). Ocul Surf. 2007;5(2):153-62.

15. Guedes RAP, Guedes VMP, Chaoubah A. Cost-effectiveness of prostaglandin analogues in Brazil. Revista Brasileira de Oftalmologia. 2008;67:281-6.

16. Roizenblatt R, Freitas Dd, Belfort Jr. R, Hofling-Lima AL, Prata Jr. JA. Economic impact of glaucoma treatment: Brazilian and North-american antiglaucomatous eyedrop volumes. Arquivos Brasileiros de Oftalmologia. 2001;64:143-6.

17. Sklubalova Z, Zatloukal Z. Classification of plastic eye dropper tips using Harkins and Brown's factor. Pharmazie. 2007;62(10):750-5.

18. Estacia P, Reginatto RS, Nunes TT, Silva TMBd, Pasqualotti A. Evaluation of the cost of lubricating eye drops based exclusively on carboxymethylcellulose in the brazilian market. Revista Brasileira de Oftalmologia. 2013;72(5):331-4.

19. German EJ, Hurst MA, Wood D. Reliability of drop size from multi-dose eye drop bottles: is it cause for concern? Eye (Lond). 1999;13(Pt 1):93-100.

20. Nagataki S, Mishima S. Pharmacokinetics of instilled drugs in the human eye. Int Ophthalmol Clin. 1980;20(3):33-49.

21. Instituto Brasileiro de Geografia e Estatística (IBGE). Projeção da população do Brasil e das unidades da federação: < http:// www.ibge.gov.br/apps/populacao/projecao/>. Accessed in 09th September, 2015.

22. Sasso M, Natalini M, Amodio D. Digital Image Processing for Quality Control on Injection Molding Products, Applications and Experiences of Quality Control: Prof. Ognyan Ivanov (Ed.), InTech. Available from: http://www.intechopen.com/books/ applications-and-experiences-of-quality-control/digital-imageprocessing-for-quality-control-on-injection-molding-products; 2011.

23. Whelan PF, Molloy D. Machine Vision Algorithms in Java. Techniques and Implementation.: Springer-Verlag London; 2001. XVIl, 284 p.

24. Frick MADA. Caracterização de minério de ferro por visão computacional. [Master's Thesis]: Federal University of Santa Maria, Brazil; 2008.

25. Steger C, Ulrich M, Wiedemann C. Machine vision algorithms and applications. 2nd. ed. New York: Wiley; 2007. 370 p.

26. Silva LR, de Paula JS, Rocha EM, Rodrigues Mde L. Factors related to glaucoma treatment compliance: patients' opinions from a University Hospital. Arq Bras Oftalmol. 2010;73(2):116-9.

27. Lee YC, Simamora P, Pinsuwan S, Yalkowsky SH. Review on the systemic delivery of insulin via the ocular route. Int J Pharm. 2002; 233(1-2):1-18.

28. Urtti A, Salminen L. Minimizing systemic absorption of topically administered ophthalmic drugs. Surv Ophthalmol. 1993;37(6):435-56.

29. Van Santvliet L, Ludwig A. Determinants of eye drop size. Surv Ophthalmol. 2004;49(2):197-213.

30. Nascimento VS, Cristovam PC, Covre JL, Gomes JÁP, Freitas Dd, Santos VR. Variation in the volume of lubricating eyedrops available in the brazilian market. Revista Brasileira de Oftalmologia. 2017;76:23-7.

31. Gaynes Bl, Singa RM, Schaab G, Sorokin Y. Impact of administration angle on the cost of artificial tear solutions: does bottle positioning minimize wastage? J Ocul Pharmacol Ther. 2007;23(2):196-201.

32. Rosato DV, Rosato DV, Rosato MG. Injection Molding Handbook: Kluwer Academic Publishers; 2000. 